\title{
Expression of hypoxia-inducible protein 2 in renal cell carcinoma: A promising candidate for molecular targeting therapy
}

\author{
TAKASHI SEO ${ }^{1}$, RYUICHIRO KONDA ${ }^{2}$, JUN SUGIMURA ${ }^{1}$, KAZUHIRO IWASAKI ${ }^{1}$, \\ YUSUKE NAKAMURA ${ }^{2,3}$ and TOMOAKI FUJIOKA ${ }^{1}$ \\ ${ }^{1}$ Department of Urology, Iwate Medical University School of Medicine, Morioka; \\ ${ }^{2}$ Department of Urology, Yamamoto Kumiai General Hospital, Noshiro; ${ }^{3}$ Laboratory of Molecular Medicine, \\ Human Genome Center, Institute of Medical Science, The University of Tokyo, Tokyo, Japan
}

Received January 20, 2010; Accepted May 20, 2010

DOI: 10.3892/ol_00000122

\begin{abstract}
This study investigated the expression of hypoxiainducible protein 2 (HIG2), a novel renal cell carcinoma (RCC)-associated molecule and an essential growth factor for $\mathrm{RCC}$, in kidneys to elucidate its clinical significance in RCC. An immunohistochemical study of HIG2 was conducted in 93 surgical samples of RCC tissues and 10 samples of normal kidney tissues obtained after nephrectomies for localized RCC. HIG2 expression was also correlated with clinicopathological characteristics and survival. Only faint or weak immunostaining for HIG2 was observed in normal kidney samples. HIG2 expression was found in $86 \%$ of RCC tissues (80/93). When analyzed by histological type, positive staining for HIG2 was detected in all papillary (7/7), chromophobe (1/1) and cyst-associated (3/3) RCC. In contrast, the HIG2 expression was observed in $85 \%$ of clear cell $(68 / 80)$ and $50 \%$ of spindle cell (1/2) RCC. Labeling indices were 74.1, 45.4, 39, 24.8 and $12.1 \%$ in papillary, spindle, clear cell, cyst-associated and chromophobe RCC, respectively. A significant increase in HIG2 expression was noted in RCC tissues obtained from patients with high stage RCC, lymph node metastasis and high nuclear grade $(\mathrm{p}<0.001, \mathrm{p}<0.02$ and $\mathrm{p}<0.006$, respectively). RCC patients with a negative HIG2 staining had prolonged 5-year cancer-specific survival. In conclusion, HIG2 expression was extensively observed in RCC tissues and was higher in advanced RCC, suggesting that HIG2 is a candidate for the development of molecular targeting therapy.
\end{abstract}

\section{Introduction}

Surgical resection is considered to be the only effective treatment for localized renal cell carcinoma (RCC). However,

Correspondence to: Dr Ryuichiro Konda, Department of Urology, Yamamoto Kumiai General Hospital, 016-0014 Ochiai, Noshiro, Japan

E-mail:konda@yamamoto-hosp.noshiro.akita.jp

Key words: renal cell carcinoma, hypoxia-inducible protein 2, tumor stage, nuclear grade, cancer-specific survival
$20-40 \%$ of surgically treated patients experience recurrence of the disease $(1,2)$. Moreover, up to $30 \%$ of patients with RCC present with metastatic disease $(2,3)$. Immunotherapies using interferons and interleukin-2 have been used for advanced RCC since this tumor is unresponsive to radiotherapy and also refractory to chemotherapy (4). However, the two therapies, alone and in combination, have demonstrated disappointing success rates of $20 \%$ or lower $(2,4)$. Up to $80 \%$ of clear cell $\mathrm{RCC}$, the most common histological subtype of RCC, show inactivation of the von Hippel-Lindau gene (VHL) that regulates the expression of hypoxia-inducible factor- $1 \alpha$ (HIF-1 $\alpha)$ $(2,4,5)$. Inactivation of VHL upregulates HIF-1 $\alpha$ production, leading to the activation of various genes containing hypoxia response elements, including the vascular endothelial growth factor (VEGF), platelet-derived growth factor (PDGF), epidermal growth factor receptor type 1, transforming growth factor- $\alpha$ and glucose transporter genes $(5,6)$. Molecular targeting agents such as sunitinib and sorafenib that target receptor protein-tyrosine kinases, including VEGF and PDGF receptors, were shown to be effective as first- or second-line treatment for metastatic RCC $(1,2,4,5)$. These agents exhibit anti-tumor activities mainly by inhibiting neovascular formation via the VEGF and PDGF pathways.

Hypoxia-inducible protein 2 (HIG2), a novel hypoxia inducible gene, is expressed exclusively in RCC. Inhibition of the HIG2 expression by small-interfering RNA significantly suppresses the growth of human RCC cells (7). The addition of polyclonal anti-HIG2 antibody to culture medium induces apoptosis in RCC cell lines. By contrast, the addition of HIG2 protein to culture medium enhances the growth of human RCC cells. These findings indicate that HIG2 is an essential growth factor for RCC. Moreover, HIG2 expression is not regulated by VHL. In RCC, the absence of VHL mutation is associated with a more advanced tumor and a poorer prognosis $(8,9)$. Molecular-targeting agents used for advanced RCC exhibit anti-tumor activity mainly via suppression of the VHL/HIF-1 $\alpha$ pathway $(1,4,5,10)$. Toxicities by these agents are caused by suppression of the signal transduction that is essential for the maintenance of various organ conditions. HIG2 expression is minimal or absent in normal human organs including the liver, heart, kidney, lung prostate and spinal cord (7). In addition, HIG2 expression is observed 
exclusively in RCC tissues. These observations suggest that HIG2 is a candidate target for the development of moleculartargeting therapy for advanced RCC. However, few studies have examined the expression of HIG2 mRNA and protein in RCC tissues, and the little available data are restricted to clear cell RCC including the granular type (7). This study aimed to elucidate HIG2 expression in a variety of RCC histological types and analyze the correlation between HIG2 expression and clinicopathological findings or patient survival.

\section{Materials and methods}

Tissue samples and patients. This study was conducted after approval by the institutional review board was obtained. A total of 93 surgical specimens of primary RCC were obtained from 65 males and 28 females who underwent radical nephrectomy between January 1991 and December 2001 at the Department of Urology, Iwate Medical University School of Medicine, Japan. The median age of these patients was 62.5 years (range 35-87). A total of 20 normal renal tissue samples were obtained from nephrectomies for localized RCC (pT1) as controls. For histological and immunohistochemical analysis, the renal tissue samples were fixed in $20 \%$ buffered formalin, embedded in paraffin and cut into $3-\mu \mathrm{m}$ sections. The sections were stained with hematoxylin and eosin for routine histological examination. Table I shows patient characteristics, including gender distribution, age, pathological stage, nuclear grade, lymph node metastasis and distant metastasis. Tumor staging was performed according to the TNM classification of malignant tumors (11). Nuclear grading was determined based on the General Rules for Clinical and Pathological Studies on Renal Cell Carcinoma as proposed by Fuhrman (11). The pathological stage was pT1a in 22 tumors, pT1b in 27, pT2 in 19, pT3a in 8, pT3b in 16 and pT4 in 1 tumor. Lymph node metastasis was found in 9 patients. Distant metastases were found in 9 patients (lung, 7; bone, 1 and liver, 1). The tumor grade was G1 in 25 cases, G2 in 62 and G3 in 6 . The histological type was clear cell in 80 tumors including 6 tumors of the granular cell, papillary in 7, cyst-associated in 3, chromophobe in 1 and spindle in 2. No patient received systemic immunotherapy prior to the nephrectomy.

Immunohistochemistry. Rabbit anti-human HIG2 antibody was used in the immunohistochemical analysis (7). Serial $3-\mu \mathrm{m}$ sections cut from paraffin-embedded specimens were deparaffinized in xylene, rehydrated in graded ethanol and immersed in $100 \%$ methanol with $0.3 \%$ hydrogen peroxide to block endogenous peroxidase activity. The sections were treated with $10 \%$ normal goat serum, then incubated with primary antibodies overnight at $4^{\circ} \mathrm{C}$. The optimal dilution of the primary antibody for HIG2 was 1:200. The sections were washed and incubated with peroxidase-conjugated goat antirabbit immunoglobulin (Envision+, Dako) for $30 \mathrm{~min}$ at room temperature. Peroxidase activity was detected by incubation in 3,3'-diaminobenzidine tetrahydrochloride solution (DAB+ liquid system, Dako). Sections were then counterstained with hematoxylin. No immunoreactivity was noted in the negativecontrol slides stained with immunoglobulin fraction from normal rabbit serum used instead of antibody.
Table I. Patient and tumor characteristics.

\begin{tabular}{|c|c|}
\hline No. of patients & 93 \\
\hline Male/female & $65 / 28$ \\
\hline \multicolumn{2}{|l|}{ Age (years) } \\
\hline Median (range) & $62.5(35-87)$ \\
\hline \multicolumn{2}{|l|}{ Tumor stage } \\
\hline pT1a & 22 \\
\hline $\mathrm{pT} 1 \mathrm{~b}$ & 27 \\
\hline pT2 & 19 \\
\hline pT3a & 8 \\
\hline pT3b & 16 \\
\hline pT4 & 1 \\
\hline \multicolumn{2}{|l|}{ Lymph node status } \\
\hline N0 & 62 \\
\hline $\mathrm{N} 1$ or $\mathrm{pN} 2$ & 9 \\
\hline NX & 22 \\
\hline \multicolumn{2}{|l|}{ Distant metastasis } \\
\hline M0 & 84 \\
\hline M1 & 9 \\
\hline \multicolumn{2}{|l|}{ Site of metastasis } \\
\hline Lung & 7 \\
\hline Lung and brain & 1 \\
\hline Bone & 1 \\
\hline \multicolumn{2}{|l|}{ Nuclear grade } \\
\hline G1 & 25 \\
\hline G2 & 62 \\
\hline G3 & 6 \\
\hline
\end{tabular}

Quantitative analysis of immunohistochemical staining. For each tumor specimen, at least 20 high-power fields were examined, and 1,000 tumor cells per specimen were counted. For semi-quantitative analysis, the amount of HIG2-positive cells was calculated and expressed as labeling index (LI). The distribution of immunostaining was graded as negative (no staining or LI $<10$ ), focal (LI 10-25), regional (LI 26-50) or diffuse (LI >50).

Statistical analysis. Cancer-specific survival was shown as Kaplan-Meier survival curves. The differences between groups were analyzed using Mann-Whitney U or Kruskal-Wallis tests. $\mathrm{P}<0.05$ was considered to be statistically significant. Statistical analysis was performed using statistical software (StatView version 5.0, SAS Institute, Inc. NC, USA).

\section{Results}

Immunohistochemical staining for HIG2. In normal kidney tissues only faint staining for HIG2 was observed (Fig. 1A). Positive staining for HIG2 was observed in 80/93 RCC tissues (86\%) (Fig. 1B-F). In clear cell RCC, 68/80 cases (85\%) showed positive staining for HIG2. Among clear cell RCC, 6 tumors were granular type. The granular cell RCC expressed HIG2. 

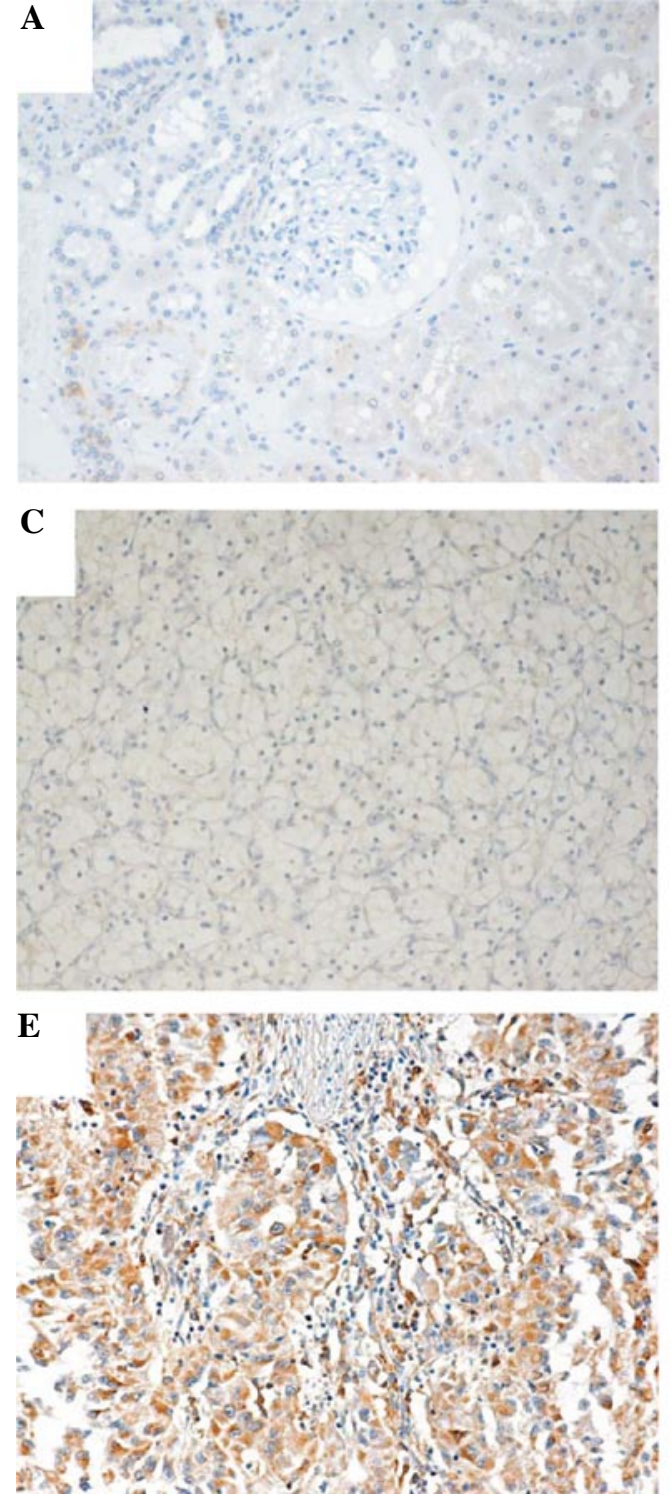
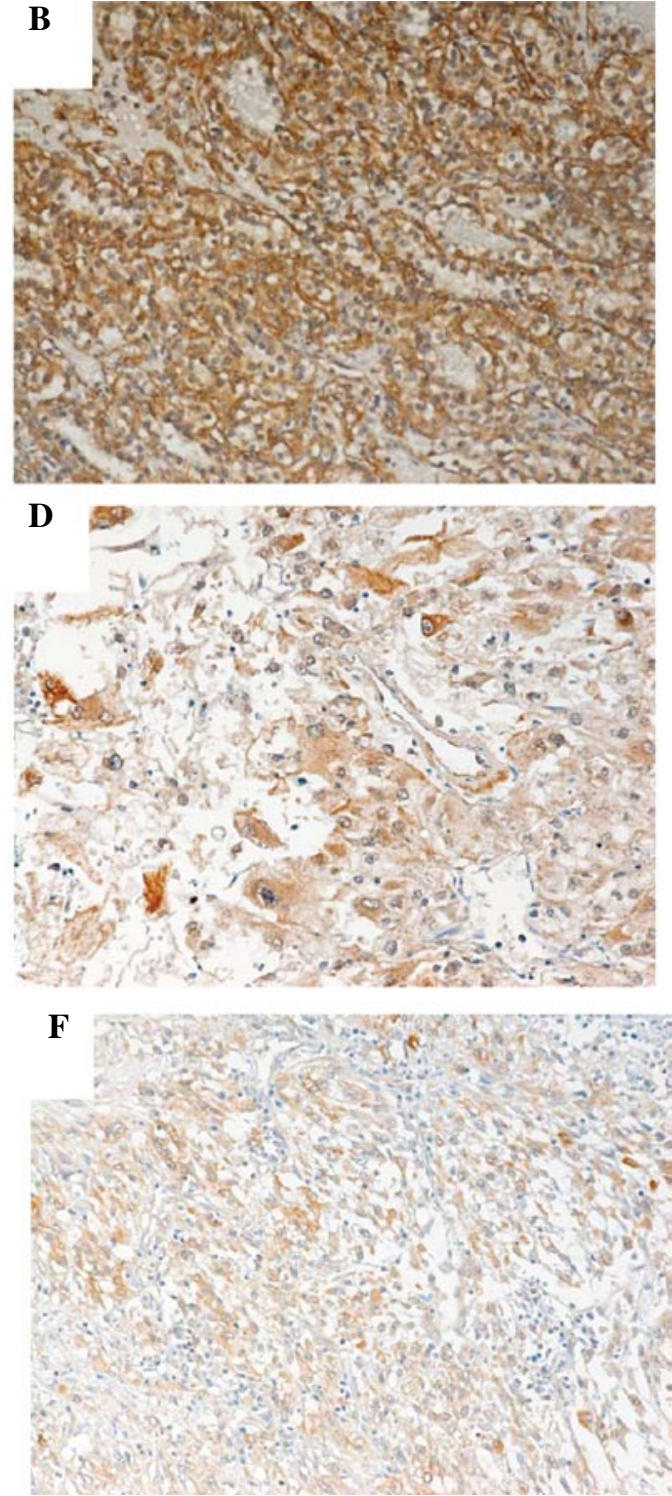

Figure 1. Immunohistochemical staining of HIG2 in (A) normal kidney tissue and (B-F) RCC tissues. (A) HIG2 expression is rarely observed in normal kidney tissue. (B) Positive staining of HIG2 in clear cell RCC. (C) Negative control of a clear cell RCC section. (D) Positive staining of HIG2 in papillary RCC. (E) Positive staining in chromophobe RCC. (F) Positive staining in spindle cell RCC. (Magnification, x200).

Table II. Positive staining for HIG2 according to the histological type.

\begin{tabular}{lc}
\hline Histological type & Percent HIG2-positivity \\
\hline Clear cell carcinoma & $85(68 / 80)$ \\
Papillary cell carcinoma & $100(7 / 7)$ \\
Chromophobe cell carcinoma & $100(1 / 1)$ \\
Spindle cell carcinoma & $50(1 / 2)$ \\
Cyst-associated RCC & $100(3 / 3)$ \\
\hline
\end{tabular}

The papillary, cyst-associated and chromophobe RCC showed positive staining for HIG2 (Table II). The mean LI were 39, $66.8,12.1,45.4$ and 24.8 in clear cell, papillary, chromophobe, spindle cell and cyst-associated RCC, respectively (Table III). The mean LI in granular type RCC was 39.
Table III. HIG2 labeling indices (LI) according to histological type.

\begin{tabular}{lc}
\hline Histological type & LI $\%($ mean \pm SD) \\
\hline Clear cell carcinoma & $39.0 \pm 2.98$ \\
Papillary cell carcinoma & $66.8 \pm 11.0$ \\
Chromophobe cell carcinoma & 12.1 \\
Spindle cell carcinoma & 45.4 \\
Cyst-associated RCC & $24.8 \pm 1.63$
\end{tabular}

HIG2 expression and clinicopathological data. No significant difference in positive staining for HIG2 was detected between male and female patients (Table IV). Positive staining for HIG2 increased with increasing pathological stage or nuclear grade $(\mathrm{p}<0.001$ and $\mathrm{p}<0.006$, respectively). Moreover, a significantly 
Table IV. HIG2 expression and clinopathological data.

\begin{tabular}{|c|c|c|c|c|c|c|}
\hline & \multirow{2}{*}{$\begin{array}{l}\text { Total no. } \\
\text { of patients }\end{array}$} & \multicolumn{5}{|c|}{ No. of patients with each grade of HIG2 expression } \\
\hline & & Negative & Weak & Moderate & Strong & $\mathrm{p}$ \\
\hline Gender & & & & & & 0.49 \\
\hline Male & 65 & 8 & 12 & 24 & 21 & \\
\hline Female & 28 & 5 & 6 & 9 & 8 & \\
\hline T stage & & & & & & $<0.001$ \\
\hline pT1 & 49 & 7 & 9 & 22 & 11 & \\
\hline pT2 & 19 & 2 & 6 & 4 & 7 & \\
\hline pT3 & 24 & 4 & 3 & 7 & 10 & \\
\hline pT4 & 1 & 0 & 0 & 0 & 1 & \\
\hline LN status & & & & & & $<0.02$ \\
\hline $\mathrm{LN}^{-}$ & 62 & 11 & 16 & 19 & 16 & \\
\hline $\mathrm{LN}^{+}$ & 9 & 0 & 0 & 3 & 6 & \\
\hline LNx & 22 & 2 & 2 & 11 & 7 & \\
\hline Nuclear grade & & & & & & $<0.006$ \\
\hline G1 & 25 & 6 & 8 & 8 & 3 & \\
\hline $\mathrm{G} 2$ & 62 & 6 & 10 & 25 & 21 & \\
\hline G3 & 6 & 1 & 0 & 0 & 5 & \\
\hline
\end{tabular}

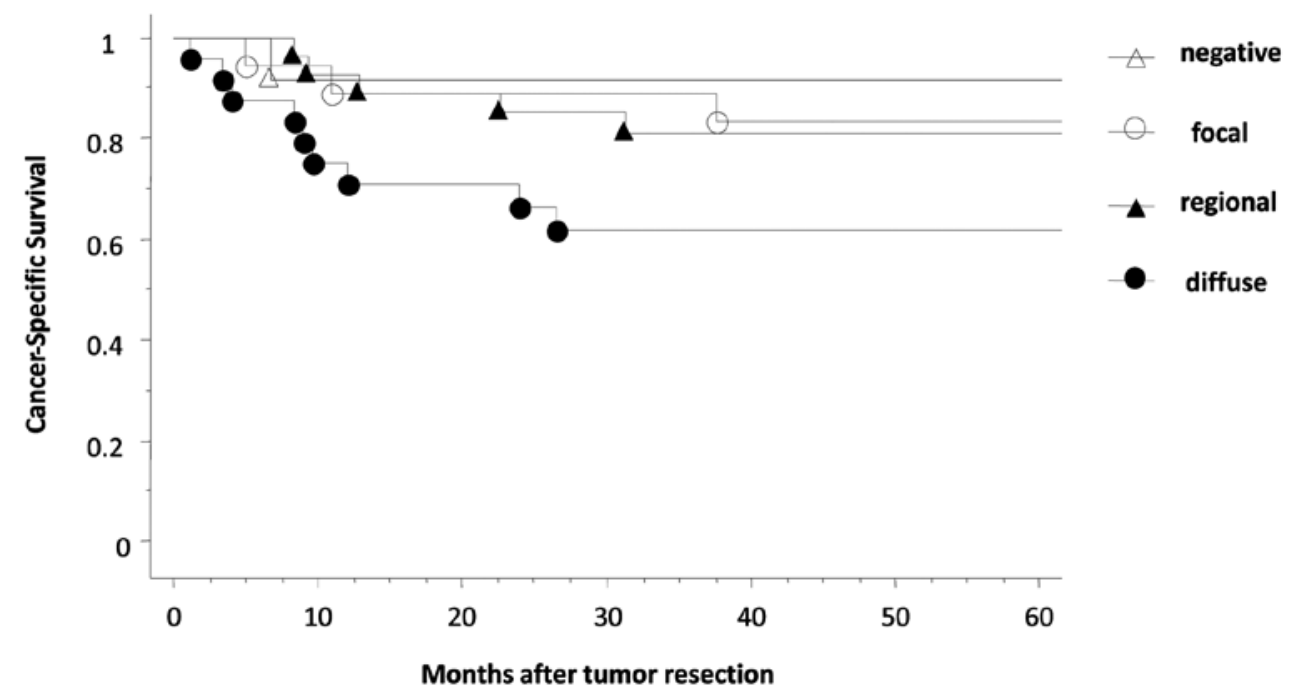

Figure 2. Kaplan-Meier survival plot showing cancer-specific survival in relation to the distribution of HIG2 staining in patients with renal cell carcinoma.

higher percentage of HIG2-positive staining was observed in RCC that metastasized to the lymph node compared to that which did not metastasize $(\mathrm{p}<0.02)$.

HIG2 expression and patient survival. The 5-year cancerspecific survival rate was $81 \%$. Patients with RCC showing negative HIG2 immunostaining exhibited an apparently higher 5-year cancer-specific survival rate compared to those with RCC showing positive staining for HIG2 (5-year cancerspecific survival was $91.7 \%$ in HIG2-negative RCC vs. 93.3, 71.4 and $58.3 \%$ in focal, regional and diffuse HIG2-positive RCC, respectively, although no significant difference was detected) (Fig. 2).

\section{Discussion}

An understanding of the biology and genetics of RCC is a key stage in the development of targeted therapeutic approaches for advanced RCC $(1,2,4,5,10)$. The molecular targeted therapeutic agents sunitinib and sorafenib have been shown to improve progression-free survival in patients with metastatic RCC $(1,2,4,5,10)$. Recent reports described a survival benefit associated with other targeted agents including bevacizumab, axitinib, temsirolimus and everolimun in these patients (10). The main targets of these agents are VHL/HIF-1 $\alpha$ and related pathways $(1,2,4,5,10)$. On the other hand, HIG2 is an essential growth factor for RCC, and plays a critical role in the development 
and progression of RCC via activation of the Wnt signaling pathway (7). Since over-expression of HIG2 has been demonstrated in RCC tumors with and without VHL inactivation, HIG2 expression is considered to be indirectly regulated by the VHL mutation or deletion (7). In this study, the HIG2 protein was expressed in various subtypes of RCC tumors. In addition, a significantly higher percentage of HIG2-positive staining was associated with a high pathological stage, advanced nuclear grade and lymph node metastasis, which indicate a poor prognosis. In the present as well as previous studies (7), HIG2 expression was barely detectable in adult normal kidney tissues. In addition, immunostaining for HIG2 in other adult human tissues is minimal or absent (7). Using RT-PCR analysis, a HIG2 mRNA expression is absent or scarcely detectable in tumors of other organs, including colorectal, breast and hepatocellular cancers (7). These findings suggest that HIG2 is a promising candidate for the development of molecular-targeted therapy for patients with advanced RCC. Since HIG2 promotes carcinogenesis via pathways not involving VHL/HIF-1 $\alpha$ or its related signals, the combined use of a novel HIG2-targeting agent with existing targeted therapeutic agents such as sunitinib, sorafenib and temsirolimus is expected to have additive or synergistic anti-tumor effects on RCC.

Carbonic anhydrase IX (CAIX) is a reliable diagnostic biomarker of clear cell RCC. A low level of CAIX expression in clear cell RCC (defined as $\leq 85 \%$ positivity in tumor cells) has been shown to independently predict poor prognosis $(3,8,12)$. CAIX is predominantly expressed in clear cell RCC since the expression of this molecule is regulated by the VHL/HIF- $1 \alpha$ pathway which is disarrayed in clear cell $\operatorname{RCC}(8,13)$. Clinical trials of vaccination with CA9-derived peptides and administration of the cG250 monoclonal antibody, which identifies the CAIX antigen, in patients with RCC have been conducted $(14,15)$. CAIX expression is observed in various extrarenal organs including the stomach, pancreas and small intestine (16). A high CAIX expression is considered to be a favorable prognostic marker for clear cell RCC $(3,8,9)$. CAIX expression is low in patients with clear cell RCC associated with an aggressive clinicopathological phenotype and poor survival. In such patients, targeted therapy is usually preferred as the modality of treatment. By contrast, the HIG2 expression is rarely observed in normal organs (7). The present study showed that HIG2 expression was up-regulated in patients with aggressive RCC and a poor prognosis. Moreover, various histological subtypes of RCC showed a high HIG2 expression. Compared with CAIX, we suggest that HIG2 is a more appropriate target for moleculartargeted therapy, since there are fewer adverse effects.

In conclusion, the present study demonstrated that HIG2, an essential growth factor for RCC, was widely expressed in various subtypes of RCC including granular type, which was previously reported not to express HIG2. HIG2 expression was up-regulated in RCC and associated with an aggressive clinicopathological phenotype and poor cancer-specific survival. The findings support a previous report that proposed HIG2 as a potential target for the development of molecular-targeting therapy for advanced RCC (7).

\section{References}

1. Weis RH and Lin PY: Kidney cancer: identification of novel targets for therapy. Kidney Int 69: 224-232, 2006.

2. Motzer RJ, Hutson TE, Tomczak P, Michaelson D, Bukowski M, Rixe O, Oudard S, Negrier S, Szczylik C, Kim ST, Chen I, Bycott PW, Baum CM and Figlin RA: Sunitinib vs. interferon alpha in metastatic renal-cell carcinoma. N Engl J Med 356: 115-124, 2007.

3. Kim HL, Seligson D, Liu X, Janzen N, Bui MHT, Yu H, Shi T, Figlin RA, Horvath $S$ and Belldegrun AS: Using protein expression to predict survival in clear cell renal carcinoma. Clin Cancer Res 10: 5464-5471, 2004.

4. Motzer RJ and Bukowski RM: Targeted therapy for metastatic renal cell carcinoma. J Clin Oncol 24: 5601-5608, 2006.

5. Patel PH, Chadalavada RSV, Chaganti RSK and Motzer RJ: Targeting von Hippel-Lindau pathway in renal cell carcinoma. Clin Cancer Res 12: 7215-7220, 2006.

6. Klatte T, Seligson DB, Riggs SB, Leppert JT, Berkman MK Kleid MD, Yu Hong, Kabbinavar FF, Pantuck AJ and Belldegrun AS: Hypoxia-inducible factor $\alpha$ in clear cell renal cell carcinoma. Clin Cancer Res 13: 7388-7393, 2007.

7. Togashi A, Katagiri T, Ashida S, Fujioka T, Maruyama O, Wakumoto Y, Sakamoto Y, Fujime M, Kawachi Y, Shuin T and Nakamura Y: Hypoxia-inducible protein2 (HIG2), a novel diagnostic marker for renal cell carcinoma and potential target for molecular therapy. Cancer Res 65: 4817-4826, 2005.

8. Patard JJ, Fergelot P, Karakiewicz PI, Klatte T, Trinh QD, Rioux-Leclecq N, Said JW, Belldegrun AS and Pantuck AJ: Low CAIX expression and absence of VHL gene mutation are associated with tumor aggressiveness and poor survival of clear cell carcinoma. Int J Cancer 123: 395-400, 2008.

9. Yao M, Yoshida M, Kishida T, Nakaigawa N, Baba $M$, Kobayashi K, Miura T, Moriyama M, Nagashima Y, Nakatani Y, Kubota Y and Kondo K: VHL tumor suppressor gene alterations associated with good prognosis in sporadic clear-cell renal cell carcinoma. J Natl Cancer Inst 94: 1569-1575, 2002.

10. Mizutani Y: Recent advances in molecular targeted therapy for metastatic renal cell carcinoma. Int J Urol 16: 444-448, 2009.

11. Tozawa K, Okamoto T, Kawai N, Hashimoto Y, Hayashi Y and Kohri K: Positive correlation between sialyl Lewis X expression and pathologic findings in renal cell carcinoma. Kidney Int 67: 1391-1396, 2005.

12. Liao SY, Aurelio ON, Jan K, Zavada J and Stanbridge EJ: Identification of the MN/CA9 protein as a reliable diagnostic biomarker of clear cell carcinoma of the kidney. Cancer Res 57: 2827-2831, 1997.

13. Wykoff CC, Beasley NJP, Watson PH, Turner KJ, Pastrek J, Sibtain A, Wilson GD, Turley H, Talks KL, Maxwell PH, Pugh CW, Ratcliffe PJ and Harris AL: Hypoxia-inducible expression of tumor-associated carbonic anhydrases. Cancer Res 60: 7075-7083, 2000.

14. Uemura H, Fujumoto K, Tanaka M, Yoshikawa M, Hirano Y, Uejima S, Yoshikawa K and Itoh K: A phase I trial of vaccination of CA9-derived peptides for HLA-A24-positive patients with cytokine-refractory metastatic renal cell carcinoma. Clin Cancer Res 12: 1768-1775, 2006.

15. Davis ID, Wiseman GA, Lee FT, Gansen DN, Hopkins W, Papenfuss AT, Liu Z, Moynihan TJ, Croghan GA, Adjei AA, Hoffman EW, Ingle JN, Old LJ and Scott AM: A phase 1 multiple dose, dose escalation study of cG250 monoclonal antibody in patients with advanced renal cell carcinoma. Cancer Immun 7: $13,2007$.

16. Leibovich BC, Sheinin Y, Lohse CM, Thompson RH, Cheville JC, Zavada J and Kwon ED: Carbonic anhydrase IX is not an independent predictor of outcome for patients with clear cell renal cell carcinoma. J Clin Oncol 25: 4757-4764, 2007. 